\title{
A Giant Combined Laryngomucocele
}

\author{
${ }^{1}$ Vivek Vishwas Harkare, ${ }^{2}$ Kanchan Sandeep Dhote, ${ }^{3}$ Nitin Vasant Deosthale, ${ }^{4}$ Sonali Prabhakar Khadakkar \\ ${ }^{5}$ Priti Rakesh Dhoke, ${ }^{6}$ B hanupratap Surendrakumar Singh
}

\begin{abstract}
Laryngomucocele is a rare benign laryngeal disease characterized by cystic dilatation of laryngeal saccule with collection of mucous in it. The etiology behind its occurrence is still unclear, but congenital and acquired factors have been implicated in its development. Although it is a benign lesion, its presence in an old patient since many days should prompt the examiner to diligently search for laryngeal malignancy. We are presenting the case of a 61 years old male who presented with swelling in the neck, hoarseness of voice, dysphagia and dyspnea on exertion. The patient was thoroughly evaluated clinically, endoscopically and radiologically. He was diagnosed to be suffering from laryngomucocele and was managed by an external lateral cervical approach.
\end{abstract}

Keywords: Laryngomucocele, Laryngocele, Larynx.

How to cite this article: Harkare VV, Dhote KS, Deosthale NV, Khadakkar SP, Dhoke PR, Singh BS. A Giant Combined Laryngomucocele. Int J Head Neck Surg 2014;5(1):45-47.

\section{Source of support $\mathrm{Nil}$}

Conflict of interest None

\section{INTRODUCTION}

Laryngocele is defined as an abnormal dilatation or herniation of the saccule of the larynx. Laryngoceles can be classified into three types: internal, external and combined. The correlation of laryngocele and laryngeal carcinoma is still being debated. Laryngocele may be seen in certain professions where high intraglottic pressure needs to be maintained for a long period of time, but it is not necessary that such a history be present in all cases. Patient presents generally with hoarseness of voice and swelling in the neck. Definitive diagnosis is made by computed tomography (CT) or magnetic resonance imaging (M RI) scans. Treatment is endoscopic marsupialization for internal laryngocele and external approach for external or recurrent laryngoceles.

\footnotetext{
${ }^{1} \mathrm{P}$ rofessor and Head, ${ }^{2,4}$ Assistant Lecturer, ${ }^{3}$ Professor

${ }^{5}$ Lecturer, ${ }^{6}$ J unior Resident

${ }^{1-6}$ Department of ENT, NKP S alve Institute of Medical S ciences and Research Centre and Lata Mangeshkar Hospital, Nagpur Maharashtra, India
}

Corresponding Author: Vivek Vishwas Harkare, Professor and Head, Department of ENT, NKP Salve Institute of Medical Sciences and Research Centre and Lata Mangeshkar Hospital Nagpur, Maharashtra, India, Phone: 9422105174, e-mail: viv_harkare@ rediffmail.com

\section{CASE REPORT}

A 61 years old male presented in ENT OPD with a history of progressive swelling in the right side of neck and hoarseness of voice since 3 years. He had difficulty in swallowing solids and dyspnea on exertion from 6 months. He gave a history of the swelling, getting aggravated on doing strenuous activity. The swelling which was initially reducible, became nonreducible from the past one and a half years. He is a farmer by occupation and used to sing devotional songs aloud.

On examination, there was a swelling over the right side of neck medial to anterior border of sternocleidomastoid with approximately $6 \times 4 \mathrm{~cm}$ in size extending vertically from hyoid bone to cricoid cartilage. The swelling was cystic, nontender and compressible but nonreducible. The swelling became prominent on performing Valsal va maneuver (Fig. 1).

Indirect laryngoscopy showed bulge at right valeculla pushing the epiglottis and laryngeal inlet toward the left, right pyriform sinus could not be seen (Fig. 2). Seventy degree endoscopy was done to confirm our findings. Ultrasound of the neck revealed cystic swelling in the right paralaryngeal region with dehiscence in the thyrohyoid membrane. Thick fluid was aspirated on fine needle aspiration cytology (FNAC) which showed no inflammatory or malignant cells. Computed tomography scan of the neck revealed a large rim enhancing dumb-bell shaped cystic lesion on right side of neck at the level of larynx with superficial and deep components, possibly a mixed fluid filled laryngocele (Fig. 3). A presumptive diagnosis of mixed laryngomucocele

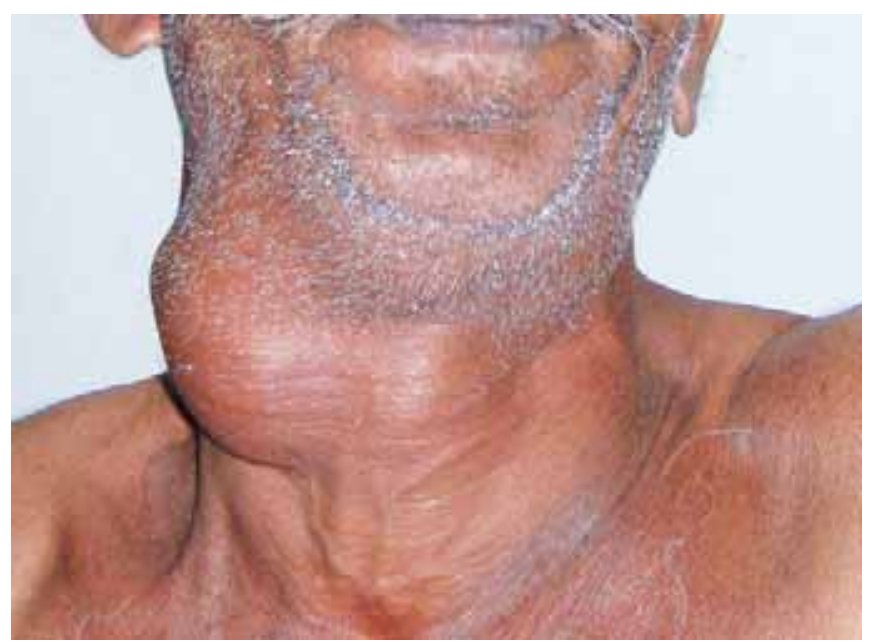

Fig. 1: The neck becoming prominent on valsalva maneuver 
was made and the patient was managed by doing complete surgical excision by external lateral cervical approach. The external and internal components were communicating through a defect in the thyrohyoid membrane. Right-sided superior laryngeal nerve was identified and preserved. A triangular wedge of thy roid cartilage was resected in order to gain accesses to the internal part. The laryngomucocele was removed in toto and the neck of saccule was ligated. There were no complications during or after surgery. Histopathology of the specimen revealed cyst wall lined with respiratory epithelium, and there was no evidence of any malignancy. The patient is under follow-up from the past one and a half years and has been asymptomatic till date (Fig. 4).

\section{DISCUSSION}

Laryngocele was first described by Virchow in 1863. He used the term 'Iaryngocele ventricularis' to describe an anomalous air sac, communicating with the laryngeal ventricle. U pward extension from the anterior end of the

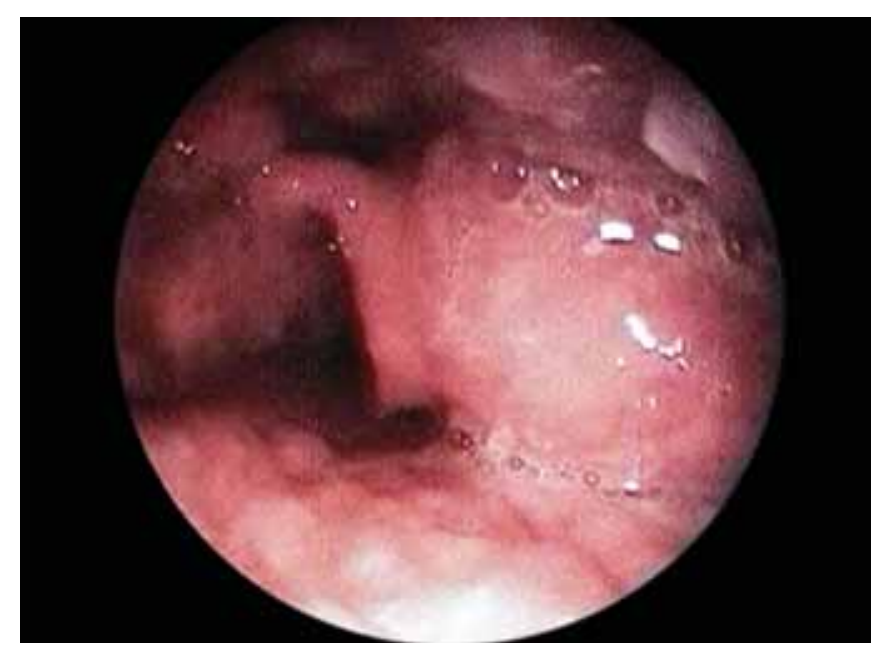

Fig. 2: Preoperative endoscopic view showing internal component of laryngomucocele

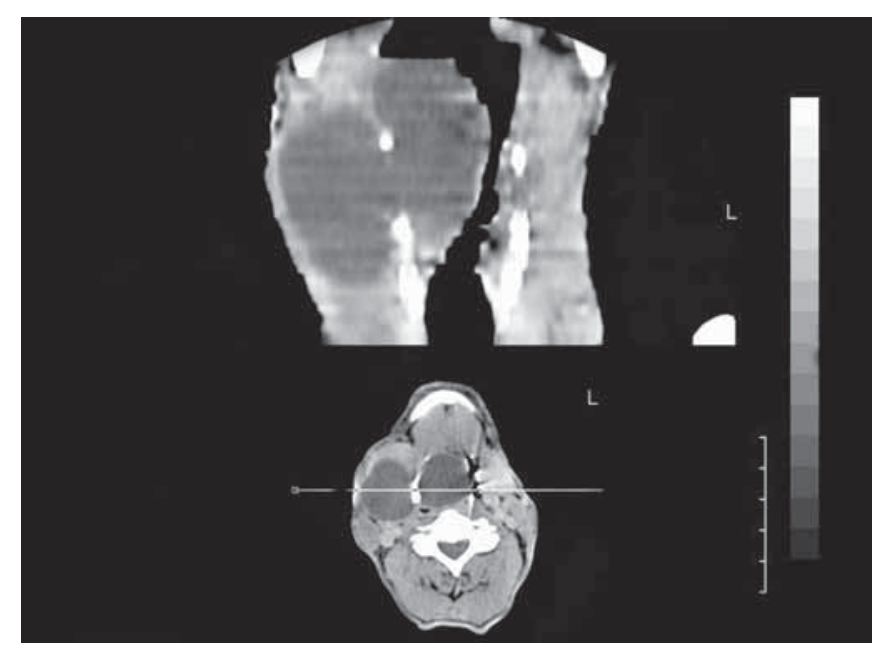

Fig. 3: Computed tomography scan of the neck revealed a large rim enhancing dumb-bell-shaped cystic lesion on the right side of the neck laryngeal ventricle is the laryngeal saccule. ${ }^{1}$ Saccule is a pouch arising from the anterior end of laryngeal ventricle. The laryngeal ventricle is the space between the vocal and vestibular folds. Saccule extends superiorly between false vocal fold and the inner surface of thyroid cartilage. A laryngocele is an abnormal dilatation or herniation of the saccule that communicates with the lumen of the larynx, and is air filled. If the communication between the laryngocele and the laryngeal lumen gets occluded then fluid gets accumulated within the sac. If the accumulated fluid is mucoid in nature the term 'laryngomucocele' is used or if it gets secondarily infected and pus gets accumulated then 'laryngopyocele' is used to define the mass.

Laryngocele has a male predominance with male to female ratio of $5: 1$ and peak incidence is in the sixth decade of life. ${ }^{2}$ L aryngoceles may be congenital or acquired. Although the etiology remains unclear but few propose that the cause of acquired laryngocele may be a significant increase in intralaryngeal pressure for a long period as in glass blowers, wind instrument players and singers. Chronic cough could be one of the precipitating factors. Certain conditions can cause the closure of the neck of saccule leading to laryngocel e formation by a flap valve mechanism, i.e. allowing entry of air in the saccule but preventing its egress like neoplasm associated with ventricle and false cord, inflammatory conditions and sometimes trauma. ${ }^{3,4}$

Three types of laryngoceles have been described. Internal laryngocele is one which is confined to the interior of the larynx and extends posterosuperiorly into the false cord and the aryepiglottic fold. ${ }^{5}$ If the laryngocele extends superiorly and appears laterally in neck through an opening in the thyrohyoid membrane, this is external laryngocele. ${ }^{6}$ Combined type has an external swelling in the thyrohyoid region which expands on coughing and empties on digtal pressure and an internal component seen as a smooth

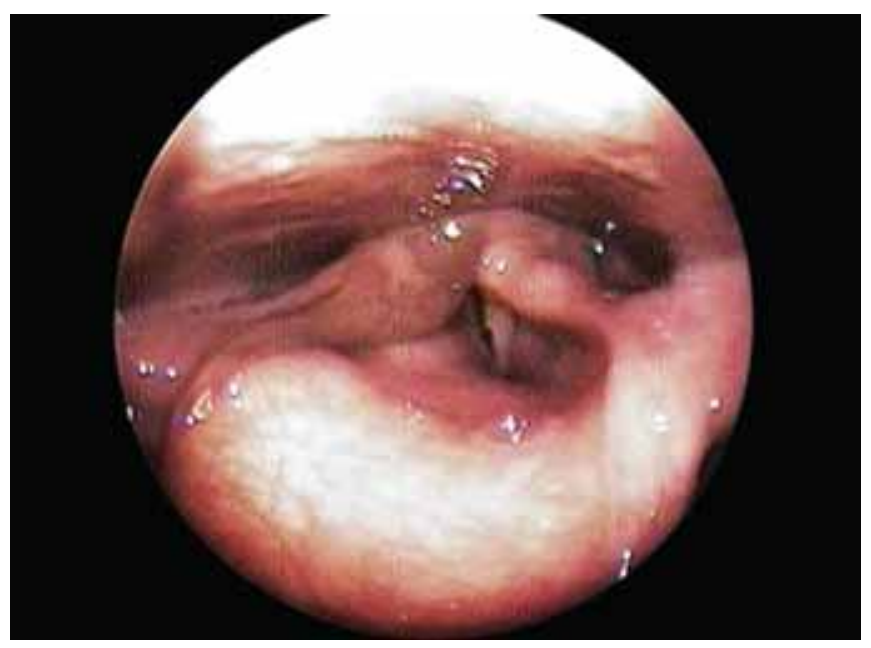

Fig. 4: Postoperative endoscopic view showing normally aligned larynx 
submucosal swelling in the valeculla and obliterating the pharyngoepiglottic fold.

Combined laryngocele appears to be the most common type of laryngoceles as compared to external or internal types. Classically, the swelling will increase during a val salva maneuver and become smaller on palpation. Internal and combined laryngoceles appear on laryngoscopy as a smooth swelling of supraglottis.

Laryngocele may be asymptomatic and often incidentally discovered through radiographic studies for unrelated diseases. ${ }^{7}$ Patient presents mainly with airway obstruction, stridor, hoarseness, sore throat, cough, pain or an externally pal pable mass. It has been documented that laryngomucocele are associated with laryngeal carcinoma. ${ }^{8}$ External laryngocele has be found in $16 \%$ of laryngectomized specimen operated for laryngeal carcinoma. Patients with external or mixed laryngocele may present with a swelling on one or both sides of the neck, which is usually compressible and increase in size on performing valsalva maneuver. There is no predominance of occurrence on left or right side.

The diagnosis can be reached by assessing the patient clinically, by doing a laryngoscopy (direct/fiberoptic) and imaging studies including soft tissue radiograph and $\mathrm{CT}$ of the neck and MRI. Magnetic resonance imaging appears now to be the modality of choice due to better soft tissue resolution.

A symptomatic lesion can be managed conservatively. Symptomatic lesions have to undergo surgical excision. Cosmetic disfigurement is a relative indication for excision. $M$ anagement depends upon the size of the lesion. L aryngoceles have traditionally been treated through an external approach. M yssiorek et al ${ }^{9}$ have used lateral laryngectomy approach for resection of laryngoceles and stated that the external approach without tracheostomy allowed for good exposure with minimal functional disability. Small internal laryngoceles can be approached using a $\mathrm{CO}_{2}$ laser endoscopically or by an external incision. External or combined laryngoceles need an external cervical approach. In combined laryngocele, removal of a triangular wedge of thyroid lamina gives a wide exposure to paraglottic space, thus helping in dissection of the internal component of the laryngocele. The external lateral cervical approach hardly causes any functional disability. During the procedure, the superior laryngeal nerve must be identified and carefully preserved as it could be intimately related to the mass.

\section{CONCLUSION}

L aryngomucocele is a rare benign laryngeal disease which is often asymptomatic. The present case is of interest because the patient was affected by a very large nonreducible external swelling, presented with exertional dyspnea, hoarseness of voice and dyphagia. The present case was thoroughly investigated with an interest to rule out associated laryngeal cancer which is a common cause for laryngomucocele in an el derly person. A n external lateral cervical approach to the laryngomucocele gave an adequate exposure and postoperative recovery was free of complications. There was no recurrence on follow-up for one and half years.

\section{REFERENCES}

1. M CD onald SE, Pinder DK, Sen C, B irchall M A. O ncocytic cyst presenting as laryngocele with surgical emphysema. Eur A rch Otorhinolaryngol 2006;263(3):237-240.

2. Rosso M, et al. Bilateral laryngoceles in association with squamous cell carcinoma: a case report and literature review. Coll A ntropol 2010;34(2):727-730.

3. Cassano L, L ombardo P, Rangona RM , Pastore A . L aryngopyocele: Three new clinical cases and review of literature. Eur A rch Otorhinolaryngol 2000;257:507-511.

4. Rosen CA, Simpson CB. Excision of combined laryngocele. O perative Techniques in L aryngology. 1st ed. B erl in Heidelberg, Springer-Verlag. 2008. p. 273-277.

5. Stell PM , M aran A G . L aryngocele. J L aryngol Otol 1975;89(9): 915-924.

6. A min M, Maran A G. The aetiology of laryngocele. Clin Otolaryngol Allied Sci 1988;13(4):267-272.

7. Gallivan KH, Gallevan GJ . Bilateral mixed laryngoceles: simultaneous strobovideolaryngoscopy and external video examination. J Voice 2002;16:258-266.

8. A kbas Y, U nal M, Pata Y S. A symptomatic bilateral mixed type laryngocele and laryngeal carcinoma. Eur A rch O torhinolaryngol 2004;261:307-309.

9. Myssiorek D, M adnani D, D elacure M D. The external approach for submucosal lesions of larynx. Otolaryngol Head Neck Surg 2001;125:370-373. 